\title{
Study of Pulmonary Function Test in Newly Diagnosed Diabetes in a Tertiary Care Teaching Hospital, Kishanganj, Bihar
}

\author{
Dr. Raghwendra Singh ${ }^{1}$, Dr. Ichchhit Bharat ${ }^{2}$, Dr. Chandni Sehgal ${ }^{3}$, Dr. Sumit Sharma ${ }^{4}$, \\ Dr. Anuj Kumar Saha ${ }^{5}$, Dr. Uttam Kumar Paul ${ }^{6}$ \\ ${ }^{1,4}$ Senior Resident, Department of General Medicine, ${ }^{2}$ Senior Resident, Department of Dermatology, ${ }^{3}$ Post Graduate Trainee, \\ Department of Obstetrics \& Gynaecology, Department of Dermatology, ${ }^{5}$ Associate Professor, Department of General Medicine, \\ ${ }^{6}$ Professor, Department of General Medicine
}

Mata Gujri Memorial Medical College \& LSK Hospital, Purabbali, Dinajpur Road, Kishanganj, Bihar 855108

\begin{abstract}
Background: Diabetes mellitus (DM) is accompanied by wide spread biochemical, morphological, and functional abnormalities which may precipitate certain complications that affect the neural, cardiovascular, renal systems, and also organs and tissues like skin, liver, collagen, and elastic fibers. This study was thus conducted to determine the pattern of pulmonary function abnormalities among patients with newly diagnosed diabetes mellitus (DM) at the outpatient clinic of M.GM Medical College. Materials \& Methods: Pulmonary function tests (PFTs) were recorded in 50 diabetic patients and 50 normal healthy controls aged 30-60 years by using Helios 702 spirometer. The PFTs recorded were FVC, FEV1, FEV1/FVC, FEF25, FEF50, FEF75, FEF25-75, and peak expiratory flow rate (PEFR). HbA1c of all the patients was estimated by ion exchange resin method. PFTs of diabetic patients and controls were compared by applying Student's unpaired t test. Associations between FVC and FEV1 and HbA1c and duration of illness in diabetic patients were analyzed by applying Pearson's coefficient. Results: Mean \& SD value of fasting plasma glucose $149.2 \pm 75.6$ for case and for control group the value was $92.8 \pm 17.6$. For case group we found $66 \%$ (33) patients in restriction category and for control group the number was 7 (14\%) and the found in statistically significant. We found 12 patients with mild, 25 patients with moderate and 13 patients with high severity. Conclusion: In the present study all the pulmonary parameters, that is, FVC, FEV1, PEF, FEF25-75, MVV and FEV1/ FVC were statistically significant. On correlating the FVC and FEV1 with duration of illness and $\mathrm{HbA1c}$, we found that there was no significant correlation between them.
\end{abstract}

Keywords: Diabetes Mellitus, Pulmonary function test, Restrictive lung function, Obstructive lung function

\section{Introduction}

Diabetes Mellitus (DM) is considered as a metabolic disorder of multiple aetiologies (genetic and environmental). It is characterized by chronic hyperglycemia due to absolute or relative insulin deficiency (defects in either insulin secretion or insulin action or both). This results in disturbances of carbohydrate, protein and fat metabolism. ${ }^{[1]}$ The major side effects of diabetes mellitus are due to its microangiopathic and macroangiopathic complications, which affect eyes, kidneys, nerves, heart, major vessels and the lungs. ${ }^{[2]}$ This is typically a multiorgan chronic disease and is associated with a ten-year-shorter life expectancy due to its complications. ${ }^{[3]}$ Globally as of 2010 it was estimated that there were 285 million people with type 2 diabetes making up about $90 \%$ of diabetes cases. ${ }^{[3]}$ This is equivalent to about $6 \%$ of the world's adult population. 4 Diabetes is common both in the developed and developing world. ${ }^{[4]}$

World Health Organization estimates that more than 180 million people worldwide have diabetes, and by 2030 it is expected that this number will have doubled. ${ }^{[5]}$ There is an alarming increase in the incidence and prevalence of diabetes mellitus (DM) in Asian Indians. ${ }^{[5]}$
The lung affectation in DM has been poorly characterized while it is known that persons with DM are at increased risk of pulmonary infections, bronchiectasis and abscess, several outcomes has been described regarding the pulmonary functions. ${ }^{[6-9]}$ Abnormal phagocytic actions induced by hyperglycaemia and the impact of nonenzymatic glycation of the lung rich in collagen and elastin may lead to stiffening of the thorax and lung parenchyma are some of the reasons given for lung involvement in diabetic process. In Nigeria some authors have documented ventilatory abnormalities in patients with DM however the findings noted has not been consistent and the studies involved rather small number of diabetic patients considering the burden of the disease. ${ }^{[10-12]}$

This study was thus conducted to determine the pattern of pulmonary function abnormalities among patients with newly diagnosed diabetes mellitus (DM) at the outpatient clinic of M.GM Medical College.

\section{Aims \& Objectives}

The aim of the study was pulmonary function test in newly diagnosed diabetes mellitus conducted at MGM Medical College, and L.S.K. Hospital, Kishanganj. 


\section{International Journal of Innovative Research in Medical Science (IJIRMS) \\ Volume 03 Issue 08 August 2018, ISSN: 2455-8737, Imp. Factor - 4.102 \\ Available online at $-\underline{w w w}$.ijirms.in}

- To assess pulmonary functions using Spirometer in newly diagnosed diabetes mellitus patients and compare them with healthy control.

- To determine the pattern of pulmonary function abnormalities of newly diagnosed diabetes mellitus patients.

\section{Materials \& Methods}

Study Area: Department of Medicine, M.G.M. Medical College \& L.S.K. Hospital Kishanganj, Bihar. Study Population: Outdoor patients in the department of Medicine, M.G.M. Medical College \& L.S.K. Hospital who had newly diagnosed diabetes mellitus who were willing to be enrolled in the study.

Study Period: October 2015 to September 2017

Sample Size: Pulmonary function tests (PFTs) were recorded in 50 diabetic patients and 50 normal healthy controls aged 30-60 years by using Helios 702 spirometer. The PFTs recorded were - FVC, FEV1, FEV1/FVC, FEF25, FEF50, FEF75, FEF25-75, and peak expiratory flow rate (PEFR). HbA1c of all the patients was estimated by ion exchange resin method. PFTs of diabetic patients and controls were compared by applying Student's unpaired $t$ test. Associations between FVC and FEV1 and HbA1c and duration of illness in diabetic patients were analyzed by applying Pearson's coefficient.

Study Design: Cross sectional, observational, study.

\section{Inclusion Criteria:}

1. Patients of both sexes were included in the study

2. Newly diagnosed DM-Patients

3. Patients willing to give written informed consent for the study

4. Only OPD Patients

\section{Exclusion Criteria:}

1. Patients having complaints of recent cough, expectoration of dyspnoea

2. Known Smoker
3. Patients with any cardio respiratory illness or any other major diseases

\section{Study Tool and Study Technique:}

This was an observational study which was done in the Department of Medicine, M.G.M. Medical College \& L.S.K. Hospital Kishanganj, Bihar. Patients were suffering from diabetes mellitus and willing to participate in the study, were enrolled. A written informed consent was taken from them. History and clinical findings was noted according to the Performa. PFT was done and following investigation was followed: 1) FBS, PPBS, RBS \& HbA1c. 2) Measurements of FVC, FEV1, FEF VALUES, Forced inspiratory flow rates (FIFs), and MVV by spirometry of pulmonary function test. For all these parameters percentage of predicted values for the respective age, height, and weight were taken into consideration. Nearly $2 \mathrm{ml}$ of venous blood was collected in ethylenediamine tetra acetic acid (EDTA) bulb in all the diabetic patients with aseptic precautions. HbA1c of all the patients was estimated by ion exchange resin method by the diagnostic glycohaemoglobin kits. PFTs of diabetic patients and controls were compared by applying Student's unpaired ' $\mathrm{t}$ ' test. Correlations between FVC and FEV1 and HbA1c and duration of illness in diabetic patients were analyzed by applying Pearson's coefficient. Statistical analysis was done by using SSPS version 20 .

\section{Plan for statistical analysis of data:}

1. To describe the central tendency, mean was calculated and for variability standard deviation was calculated for groups.

2. To compare two unpaired groups unpaired $\mathrm{T}$ test was used.

3. To compare two paired groups, paired $\mathrm{T}$ test was used.

4. To quantify association between two variables Spearman correlation test was used.

\section{Results}

The present study was a case control group. It was an observational study as well and the observations are mentioned through the tables and figures given below:

Table 1: Sex wise distribution in case and control group

\begin{tabular}{|l|c|c|c|c|}
\hline \multirow{2}{*}{ Sex } & \multicolumn{2}{|c|}{ Case (n= 50) } & \multicolumn{2}{c|}{ Control (n= 50) } \\
\cline { 2 - 5 } & No. of Patients & Percentage (\%) & No. of Subjects & Percentage (\%) \\
\hline Male & 37 & 74 & 38 & 76 \\
\hline Female & 13 & 26 & 12 & 24 \\
\hline
\end{tabular}

From table 1 we found that our study comprises $74 \%$ (37) male and 26\% (13) female patients and 76\% (38) male and 24\% (12) female in case and control group respectively.

Table 2: Findings of the parameters used in Case $(n=50)$ and Control $(n=50)$ group

\begin{tabular}{|c|c|c|c|c|c|}
\hline \multirow[t]{2}{*}{ Parameters } & \multicolumn{2}{|c|}{ Case $(n=50)$} & \multicolumn{2}{|c|}{ Control $(\mathrm{n}=50)$} & \multirow[b]{2}{*}{$\mathrm{p}$ Value } \\
\hline & Mean & $\pm \mathrm{SD}$ & Mean & $\pm \mathrm{SD}$ & \\
\hline Systolic Blood Pressure $(\mathrm{mm} / \mathrm{Hg})$ & 139.5 & 34.8 & 124.5 & 38.6 & 0.29 \\
\hline Diastolic Blood Pressure $(\mathrm{mm} / \mathrm{Hg})$ & 75.2 & 16.9 & 72.2 & 18.9 & 0.64 \\
\hline Fasting Plasma Glucose (mg/dl) & 149.2 & 75.6 & 92.8 & 17.6 & 0.24 \\
\hline PP Plasma Glucose (mg/dl) & 228.4 & 112.1 & 119.6 & 19.2 & 0.31 \\
\hline HbA1c (\%) & 8.03 & 2.1 & 5.2 & 1.41 & 0.5 \\
\hline
\end{tabular}

From table 2 we found the comparison of mean and \pm SD between case and control group regarding the parameters we had used in our study. None of the parameters were significant. 
International Journal of Innovative Research in Medical Science (IJIRMS)

Volume 03 Issue 08 August 2018, ISSN: 2455-8737, Imp. Factor - 4.102

Available online at - $\underline{w w w . i j i r m s . i n}$

Table 3: Showing comparison of height, weight \& BMI in case and control group

\begin{tabular}{|c|c|c|c|c|c|}
\hline \multirow[t]{2}{*}{ Parameters } & \multicolumn{2}{|c|}{ Case $(n=50)$} & \multicolumn{2}{|c|}{ Control $(\mathrm{n}=50)$} & \multirow[b]{2}{*}{$\mathrm{p}$ Value } \\
\hline & Mean & $\pm \mathrm{SD}$ & Mean & $\pm \mathrm{SD}$ & \\
\hline Height & 156.23 & 32.14 & 159.21 & 31.4 & 0.001 \\
\hline Weight & 53.622 & 22.9 & 58.3 & 16.7 & 0.042 \\
\hline BMI & 21.854 & 75.6 & 22.9 & 17.6 & 0.24 \\
\hline
\end{tabular}

From table 3 we found the comparison of mean and \pm SD between case and control group regarding, Height Weight $\&$ BMI. We found the pvalue of height \& weight were significant and the p value of BMI was not significant.

Table 4: Showing Comparison of pulmonary function defects in case and control group

\begin{tabular}{|l|c|c|c|c|c|}
\hline \multirow{2}{*}{ Parameters } & \multicolumn{2}{|c|}{ Case $(\mathrm{n}=50)$} & \multicolumn{2}{c|}{ Control $(\mathrm{n}=50)$} & $\mathrm{p}$ Value \\
\cline { 2 - 6 } & No. of Patients & Percentage (\%) & No. of Subjects & Percentage (\%) & 14 \\
\hline Restriction & 33 & 66 & 7 & 12 & 24 \\
\hline Obstruction & 5 & 10 & 3 & 6 & 0.002 \\
\hline Mixed & 8 & 16 & 28 & 56 & 0.652 \\
\hline Normal & 4 & 8 & 0.008 \\
\hline
\end{tabular}

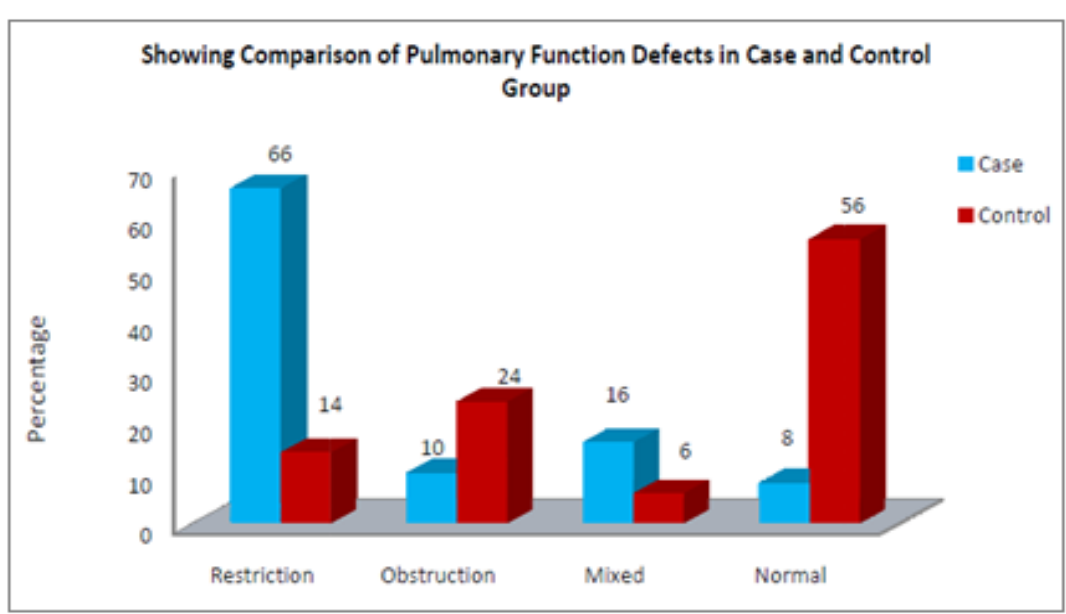

Figure 1: Showing comparison of pulmonary function defects in case and control group

Table 5: Showing comparison of pulmonary function test in case and control group

\begin{tabular}{|c|c|c|c|c|c|}
\hline \multirow[b]{2}{*}{ Pulmonary Function Test } & \multicolumn{2}{|c|}{ Case $(n=50)$} & \multicolumn{2}{|c|}{ Control $(n=50)$} & \multirow[b]{2}{*}{$\mathrm{p}$ Value } \\
\hline & Mean & $\pm \mathrm{SD}$ & Mean & $\pm \mathrm{SD}$ & \\
\hline FVC & 1.69 & 0.60 & 2.89 & 0.70 & $<0.005$ \\
\hline $\mathrm{FEV}_{1}$ & 1.38 & 0.48 & 2.41 & 0.81 & $<0.005$ \\
\hline $\mathrm{PEF}$ & 3.92 & 1.60 & 6.57 & 1.47 & $<0.005$ \\
\hline $\mathrm{FEF}_{25-75 \%}$ & 1.98 & 1.06 & 3.96 & 1.24 & $<0.005$ \\
\hline MVV & 78.04 & 19.40 & 111.60 & 34.62 & $<0.005$ \\
\hline FEV1/ FVC & 91.20 & 21.09 & 34.60 & 7.69 & $<0.005$ \\
\hline
\end{tabular}

Shows in the present study all the pulmonary parameters, that is, FVC, FEV1, PEF, FEF 25-75, MVV and FEV1/ FVC were statistically significant. The comparison of Mean \& SD of the pulmonary function test between case and control group is mentioned in table 5 .

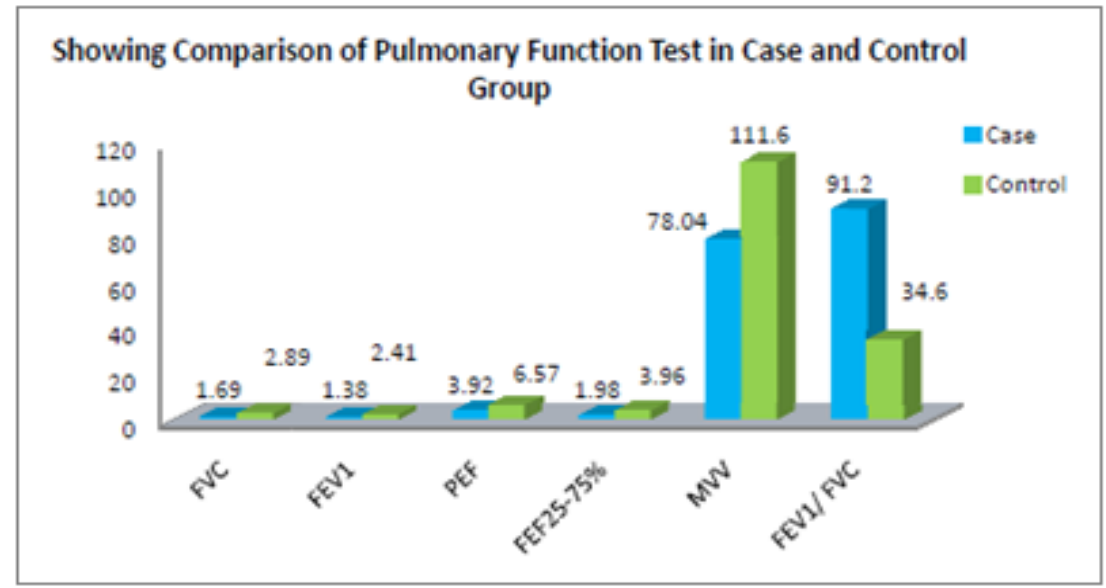

Figure 2: Showing comparison of pulmonary function test in case and control group 
International Journal of Innovative Research in Medical Science (IJIRMS)

Volume 03 Issue 08 August 2018, ISSN: 2455-8737, Imp. Factor - 4.102

Available online at - $w w w$.ijirms.in

Table 6: Showing association of pulmonary function test with diabetes severity

\begin{tabular}{|l|c|c|c|c|c|c|}
\hline Severity & $\mathrm{FVC}$ & $\mathrm{FEV}_{1}$ & $\mathrm{PEF}$ & $\mathrm{FEF}_{25-75 \%}$ & $\mathrm{MVV}$ & $\mathrm{FEV}_{1} / \mathrm{FVC}$ \\
\hline Mild $(\mathrm{n}=12)$ & $1.58 \pm 0.62$ & $1.52 \pm 0.59$ & $2.65 \pm 1.60$ & $2.01 \pm 0.86$ & $72.41 \pm 29.4$ & $79.4+14.2$ \\
\hline Moderate $(\mathrm{n}=25)$ & $1.30 \pm 0.49$ & $1.12 \pm 0.38$ & $2.79 \pm 1.20$ & $1.38 \pm 0.80$ & $60.49 \pm 18.6$ & $84.6+11.98$ \\
\hline Severe $(\mathrm{n}=13)$ & $1.49 \pm 0.68$ & $1.36 \pm 0.57$ & $3.21 \pm 1.64$ & $1.69 \pm 0.78$ & $70.21 \pm 25.1$ & $86.4 \pm 12.69$ \\
\hline P value & 0.224 & 0.621 & 0.541 & 0.223 & 0.298 & 0.231 \\
\hline
\end{tabular}

Table 6 shows the association of PFT with Diabetes severity in case group. We found 12 patients with mild, 25 patients with moderate and 13 patients with high severity. We mentioned the Mean and SD value of all the PFT parameters we used for the present mentioned in table 6 and we found all the parameters statistically significant.

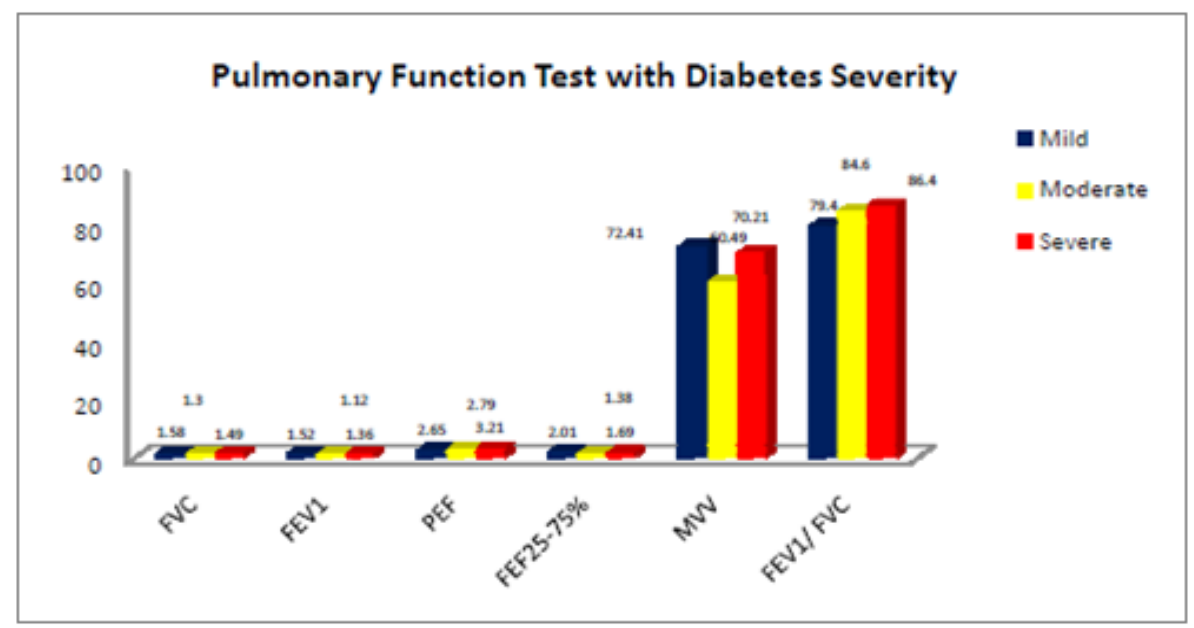

Figure 3: Showing association of pulmonary function test with diabetes severity

\section{Discussion}

Our study was pulmonary function test in newly diagnosed diabetes mellitus conducted at MGM Medical College, and L.S.K. Hospital, Kishanganj, Bihar. Pulmonary functions by PFT study in newly diagnosed diabetes mellitus patients and compare them healthy control. Determine the pattern of pulmonary function abnormalities among patients with diabetes mellitus (DM). We selected 50 patients each for case and control group. It was an observational study as well and the observations are mentioned through the Table 1 we found that our study comprises $74 \%$ (37) male and $26 \%$ (13) female patients and $76 \%$ (38) male and $24 \%$ (12) female in case and control group respectively.

Table 2 we found the comparison of mean and \pm SD between case and control group regarding the parameters we had used in our study. The mean \& SD value of systolic blood pressure was $139.5 \pm 34.8$ for case and $124.5 \pm 38.6$ for control group. Mean \& SD value of diastolic blood pressure was75.2 \pm 16.9 for case and $72.2 \pm 18.9$ for control group. Mean \& SD value of fasting plasma glucose $149.2 \pm 75.6$ for case and for control group the value was $92.8 \pm 17.6$. The mean \& SD value of post prandial plasma glucose for case and control group were $228.4 \pm 112.1$ and $119.6 \pm 19.2$ respectively. The mean and SD value of $\mathrm{HbA1c}$ was $8.03 \pm 2.1$ and $5.2 \pm 1.41$ for case and control group respectively. None of the parameters were significant.

Some of the prospective and cross sectional studies have shown low vital capacity or restrictive pattern in DM. ${ }^{[13,14]}$ Meta-analysis by van den Borst, et al. showed that DM is associated with statistically significant, impaired pulmonary function in a restrictive pattern. Moreover, these results were irrespective of body mass index (BMI), smoking, diabetes duration, and $\mathrm{HbAlc}$ levels. ${ }^{[15]}$
Table 3 shows that we compared the mean and \pm SD value of height, weight \& BMI for case and control group. For the above table we found that the mean \& SD value of height for case were $156.23 \pm 32.14$ and $159.21 \pm 31.4$ for control group respectively. The mean \& SD value of weight for case and control group was $53.622 \pm 22.9 \& 58.3 \pm 16.7$ respectively. The $p$ value was statistically significant for both height and weight. The mean \& SD value of BMI for case and control group was $21.854 \pm 79.6$ and $22.9 \pm 17.6$ respectively and we found it statistically significant.

Table 4 shows the comparison of pulmonary function defects in case and control group. For case group we found 66\% (33) patients in restriction category and for control group the number was 7 (14\%) and the found in statistically significant. In obstruction category $10 \%$ (5) patients were case group and $24 \%$ (12) patients were in control group. It was also statistically significant. For mixed category the number of patients for case and control group was $8(16 \%)$ and $3(6 \%)$ respectively. We found it statistically not significant. For normal category we found only $4(8 \%)$ patients in case group and 28(56.6\%) patients in control group and we found it statistically significant. Ehrlich, et al. showed that patients with DM were at increased risk of several pulmonary conditions like asthma, chronic obstructive pulmonary disease (COPD), fibrosis, and pneumonia. ${ }^{[16]}$

Few studies have mentioned that no significant differences were observed in patients of type $2 \mathrm{DM}^{[17,18,19]}$ Probably the small sample size is the reason behind these findings. Pathophysiology of reduced lung function is still an interesting research issue. Normal lung mechanics and gas exchange are influenced by the integrity of the pulmonary connective tissue and microvaculature. Acceleration of aging process in connective tissue cross links and presence of nonenzymatic glycosylation and modification of alveolar surfactant action causes reduction in PFTs. ${ }^{[20]}$ There have been reports of 


\section{International Journal of Innovative Research in Medical Science (IJIRMS) \\ Volume 03 Issue 08 August 2018, ISSN: 2455-8737, Imp. Factor - 4.102}

Available online at - $\underline{w w w . i j i r m s . i n}$

histopathological changes in the diabetic patients. In the study by Weynand et al., ${ }^{[21]}$ it was found that alveolar epithelium, endothelium capillary, and basal laminaes were thickened in lungs on electron microscopy, when compared with the controls. In addition, the thickening of basal laminae was of the same magnitude in lung and kidney. Diabetic microangiopathy might be existing in the pulmonary vascular bed. Moreover, reduced pulmonary capillary blood volume was found, favoring the evidence of microangiopathy. This could lead to redistribution of the pulmonary circulation, resulting in well ventilated areas to become under perfused. ${ }^{[22]}$

Table 5 shows in the present study all the pulmonary parameters, that is, FVC, $\mathrm{FEV}_{1}, \mathrm{PEF}, \mathrm{FEF}_{25-75}, \mathrm{MVV}$ and $\mathrm{FEV}_{1} / \mathrm{FVC}$ were statistically significant. The comparison of mean \& SD of the Pulmonary Function Test between case and control group is mentioned in table 5. The thorax and lungs are rich in collagen and elastin. Stiffening of thorax and lung parenchyma can occur because of nonenzymatic glycosytion of these structural compounds. This may lead to restrictive pattern. ${ }^{[20]}$ In our studies, since the FVC/FEV1 ratio is statistically not significantly different in DM patients as compared with normal controls, other PFT values are lower in DM patients; this strongly suggests restrictive pattern in DM patients. Studies have even shown diabetic polyneuropathy, which affects respiratory neuromuscular function and thus reducing pulmonary volumes. ${ }^{[23]}$ On correlating the FVC and FEV1 with duration of illness and $\mathrm{HbA} 1 \mathrm{c}$, we found that there was no significant correlation between them.

Table 6 shows the association of PFT with diabetes severity in case group. We found 12 patients with mild, 25 patients with moderate and 13 patients with high severity. We mentioned the mean and SD value of all the PFT parameters we used for the present study is mentioned in table no 6 . And we found all the parameters statistically significant. There are certain studies showing no correlation ship between HbA1c and PFTs. ${ }^{[24]}$ They argued that HbA1c levels are indicators of glycemic control for a short period of 1-2 months, it was not adequate to conclude that the plasma glucose level was not related to decreased PFTs. While some studies have shown that the decline in PFTs was negatively correlated with HbA1c. ${ }^{[25,26]}$

There are studies that have reported no significant correlation between PFTs and duration of diseases, ${ }^{[18]}$ while some of the studies have reported a strong negative correlation of PFTs with duration. ${ }^{[27,28]}$ Since DM is a disease, which involves multiple organs randomly, the study of the effect of duration of the disease on them requires further research. Several studies have analyzed the association between impaired lung function and death and found that a $10 \%$ decrease in FEV1 was associated with a $12 \%$ increase in all cause mortality in type $2 \mathrm{DM}^{\left[{ }^{[29]}\right.}$

\section{Conclusion}

Our study supports the other studies that diabetic patients showed impaired lung function independent of smoking. Restrictive lung function defect is common among patients with diabetes while clinical parameters namely ageing, high body mass index and diabetes mellitus all significantly affect the lung functions. It is therefore important to increase awareness of potential damage to the lungs in our patients with diabetes and encourage ideal BMI for this group of persons. DM being a systemic disease, also affects lungs causing restrictive type of ventilatory changes probably because of glycosylation of connective tissues, reduced pulmonary elastic recoil, and inflammatory changes in lungs. We found that glycemic levels and duration of disease are probably not the major determinants of lung pathology, which requires further research. It will also be potentially useful to offer periodic lung function as part of diabetes annual checks for early detection of lung abnormalities.

\section{References}

[1] Keerthi G, Sharan B, Hari Krishna B, Suresh M. Deterioration of pulmonary functions in type 2 diabetes mellitus J. Pharm. Biol. Sci. 2012; 1:39-43.

[2] Ali MO, Begum S, Ali T, Ferdousi S. FVC, FEV1, and FEV1/FVC\% in type 2 diabetes and their relationships with duration of the disease. J Bangladesh Soc. Physiol. 2009; 4 (2):81-87.

[3] Williams textbook of endocrinology. (12 ${ }^{\text {th }}$ ed.). Philadelphia: Elsevier/Saunders. pp. 1371-1435. ISBN 978-1-4377-0324-5.

[4] Meetoo D, McGovern P, Safadi R. An epidemiological overview of diabetes across the world. British journal of nursing (Mark Allen Publishing) 2007 Sep 13-27;16 (16): 1002-7.

[5] World Health Organization. Fact sheet: Diabetes. No. 312, November 2008.

[6] Davis WA, Knuiman M, Kendall P, Grange V, Davis TM. Glycaemic exposure is associated with reduced pulmonary function in type 2 diabetes: the free mantle Diabetes study. Diabetes care 2004; 27: 338-43.

[7] Sandlers M. Is the lung a target organ in diabetes mellitus? Arch intern Med 1990; 1507: 1385-1388.

[8] Meo SA, Ai-erees AM, Arif M, Al-Rubean K. Lung function in type 2 Saudi diabetic patients. Saudi Med J 2006; 27: 338-343.

[9] Cooper BG, Taylor R, Alberti KG, Gibson GJ. Lung function in patients with diabetes mellitus. Respir med 1990; 84: 235-239.

[10] Muller MR, Crapo R, Hankinson J. General consideration for lung function testing. EurResp J 2005; 153-161.

[11] Definition and diagnosis of diabetes mellituslibdoc.who.int-World.

whqlibdoc.who.int/publications/2006/9241594934.

[12] Vracko R, Thorning D, Huang TW. Basal lamina of alveolar Vracko R, Thorning D, Huang TW: Basal lamina of alveolar epithelium and capillaries: quantitative changes with aging and in diabetes mellitus. Am Rev Respir Dis 1979; 1205: 973-983.

[13] Engstrom GJ, Janzon L. Risk of developing diabetes is inversely related to lung function: A population based cohort study. Diabet Med. 2002; 19:167-70.

[14] Yeh HC, Punjabi NM, Wang NY, Pankow J, Duncan $\mathrm{BB}, \mathrm{Cox} \mathrm{CE}$, et al. Cross sectional and prospective study of lung function in adults with diabetes mellitus. Diabetes.2002; 51:A242-3.

[15] Borst BB, Gosker HR, Zeegers MP, Schols AM. Pulmonary function in Diabetes: A Metaanalysis. Chest. 2010; 138:393-406. 
[16] Ehrlich SF, Quesenberry CP, Vanden Eeden SK, Shan J, Ferrara A. Patients diagnosed with diabetes is at increased risk for asthma, COPD, pulmonary fibrosis and pneumonia but not lung cancer. Diabetes Care. 2010; 33:55-60.

[17] Shan-ping J, Li-wen H, Yi-qun L, Guo-juan L, He-lin D, Yan L, et al. Pulmonary function in patients with diabetes mellitus. Chin J Pathophysiol. 2005; 21:574-9.

[18] Benbassat CA, Stern E, Kramer M, Lebzelter J, Blum I, Fink G. Pulmonary function in patients with diabetes mellitus. Am J Med Sci. 2001; 322:127-32.

[19] Sinha S, Guleria R, Misra A, Pandey RM, Yadav R, Tiwari S. Pulmonary functions in patients with type 2 diabetes mellitus and correlation with anthropometry and microvascular complications. Indian J Med Res. 2004; 119:66-71.

[20] Sandler M. Is the lung is target organ in diabetes mellitus? Arch Intern Med.1990; 150:1385-8

[21] Weynand B, Jonkheree A, Frans A, Rahier J. Diabetes mellitus induces a thickening of the pulmonary basal lamina. Respiration. 1999; 66:14-9.

[22] Sandler M, Bunn AE, Stewart RI. Cross section study of pulmonary function in patients with insulin-dependent diabetes mellitus. Am Rev Respir Dis. 1987; 135:223- 9.

[23] Kabitz HJ, Sonntag F, Walker D. Diabetic polyneuropathy is associated with respiratory muscle impairment in type 2 diabetes. Diabetologia. 2008; 51:191-7.

[24] Mori H, Okubo M, Okamura M, Yamane K, Kado S, Egusa $\mathrm{G}$, et al. Abnormalities of pulmonary function in patients with non-insulin dependent diabetes mellitus. Intern Med.1992; 31:189-93.

[25] Davis WA, Knuiman M, Kendall P, Grange V, Davis TM. Glycemic exposure is associated with reduced pulmonary function in type 2 diabetes, the fremantle diabetes study. Diabetes Care. 2004; 27:752-7.

[26] Lange P, Groth S, Kastrup J, Mortensen J, Appleyard M, Nyboe J, et al. Diabetes mellitus, plasma glucose and lung function in a cross sectional population study. Eur Respir J.1989; 2:14-9.

[27] Davis TM, Knuiman M, Kendall P, Vu H, Davis WA. Reduced pulmonary function and its association in type 2 diabetes: The fremantle diabetes study. Diabetes Res Clin Pract.2000; 50:153-9.

[28] Barrett-Conor E, Frette C. NIDDM, impaired glucose tolerance, and pulmonary function in older adults. Diabetes Care. 1996; 19:1441-4.

[29] Knuiman MW, James AL, Diviniti ML, Ryan G, Bartholomew HC, Musk AW. Lung function, respiratory symptoms, and mortality: Results from the buselton health study. Ann Epidemiol. 1999; 9:297-306.

\section{*Corresponding Author -}

\section{Dr. Ichchhit Bharat}

Senior Resident, Department of Dermatology, Mata Gujri Memorial Medical College \& LSK Hospital, Purabbali, Dinajpur Road, Kishanganj, Bihar 855108 